\title{
Nephroprotective Effect of Ursolic Acid in a Murine Model of Gentamicin-Induced Renal Damage
}

\author{
Preethi G. Pai, ${ }^{1}$ Savindika Chamari Nawarathna, ${ }^{1}$ Avdhooth Kulkarni, ${ }^{1}$ Umma Habeeba, ${ }^{1}$ \\ Sudarshan Reddy C., ${ }^{1}$ Srinivas Teerthanath, ${ }^{2}$ and Jnaneshwara P. Shenoy ${ }^{3}$ \\ ${ }^{1}$ Department of Pharmacology, Kasturba Medical College, Manipal University, Mangalore 575001, Karnataka, India \\ ${ }^{2}$ Department of Pathology, K S Hegde Medical Academy, Nitte University, Deralakatte, Mangalore 574160, India \\ ${ }^{3}$ Department of Physiology, Father Muller Medical College, Mangalore 575002, India
}

Correspondence should be addressed to Preethi G. Pai, meddocpai2@yahoo.com

Received 4 April 2012; Accepted 3 May 2012

Academic Editors: J. L. Cornish and M. A. Prendergast

Copyright (c) 2012 Preethi G. Pai et al. This is an open access article distributed under the Creative Commons Attribution License, which permits unrestricted use, distribution, and reproduction in any medium, provided the original work is properly cited.

\begin{abstract}
The present study evaluates the nephroprotective effects of ursolic acid in a murine model of gentamicin induced renal damage. Wistar albino rats of either sex, weighing 150-200 g were divided into 5 groups; normal saline, gentamicin $80 \mathrm{mg} / \mathrm{kg}$, intraperitoneally for 8 days, ursolic acid at 2, 5, and $10 \mathrm{mg} / \mathrm{kg}$, per oral for 8 days, ursolic acid administered 3 days prior and concurrently with gentamicin for 5 days. Blood urea, serum creatinine, uric acid and blood urea nitrogen analyses and microscopic examination of kidney were performed. Gentamicin treatment caused nephrotoxicity as evidenced by marked elevation in serum urea, serum uric acid, serum creatinine and blood urea nitrogen $(162.33 \pm 9.92 \mathrm{mg} / \mathrm{dL}, 3.13 \pm 0.12 \mathrm{mg} / \mathrm{dL}, 6.85 \pm 0.35 \mathrm{mg} / \mathrm{dL}$ and $75.86 \pm 4.64 \mathrm{mg} / \mathrm{dL}$; resp.) when compared to the saline treated groups. Co-administration of ursolic acid with gentamicin decreased the rise in these parameters in a dose dependent manner. Histopathological analysis revealed epithelial loss with intense granular degeneration in gentamicin treated rats, whereas ursolic acid mitigated the severity of gentamicin-induced renal damage. To conclude, our data suggest that ursolic acid exhibits renoprotective effect in gentamicin induced renal damage and further studies on its mechanis of action are warranted.
\end{abstract}

\section{Introduction}

Aminoglycosides continue to represent highly effective antimicrobial agents since their introduction about more than 50 years ago [1]. Despite the introduction of highly potent, wide-spectrum antibiotics, aminoglycosides are still considered to be very important against many life-threatening infections especially against gram-negative bacterial infections [2]. They are very commonly used antibiotics worldwide because of certain properties as rapid concentration-dependent bactericidal effects, clinical effectiveness, a low rate of true resistance, synergism with other beta lactam antibiotics, and low cost of therapy $[3,4]$. However, their efficacy continues to be counterbalanced by significant toxicity especially nephrotoxicity which bring about kidney damage by a direct dose-dependent mechanism $[5,6]$.
Nephrotoxicity induced by gentamicin is a complex phenomenon characterized by increase in plasma creatinine and urea levels and severe proximal renal tubular necrosis, followed by deterioration and renal failure $[7,8]$. As gentamicin administration can induce severe nephrotoxicity, it has become a popular substance used to study druginduced acute renal failure. The toxicity of aminoglycosides, including gentamicin, is believed to be related to the generation of reactive oxygen species (ROS) in the kidney $[8,9]$. The cellular antioxidant status determines the susceptibility to oxidative damage and usually alters in response to oxidative stress [10]. Various studies have claimed antioxidant property of drugs for their nephroprotective effects in gentamicin-induced renal damage [11-14].

Ursolic acid, an ursane type triterpenoid compound which exists widely in natural plants in the form of free acid or aglycones for triterpenoid saponins [15] has emerged 
as a molecule of therapeutic importance due to its diverse pharmacological properties and lower systemic toxicities. Ursolic acid has been implicated in inhibition of lipoxygenase and cyclooxygenase in HL60 leukemic cells, inhibition of mutagenesis in bacteria, antitumor-promotion, inhibition of histamine release, inhibition of lipid peroxidation, and protection against adriamycin toxicity, antioxidant activity, hepatoprotective activity, antimicrobial activity, inhibition of mouse skin tumorigenesis, anti-inflammatory action, hypolipidemic and antiatherosclerotic effects, antiulcer activity, and cytotoxicity to leukemia cells [16]. Herbs like Momordica dioica Roxb containing ursolic acid as one of its constituents have shown significant nephroprotective activity [17]. Moreover, a closely related triterpinoid oleanolic acid has also shown nephroprotective effect [18].

However, literature research revealed that the nephroprotective activity of ursolic acid in its pure form has not been established and its probable role has only been postulated with no positive evidence. Hence with this background we decided to explore the nephroprotective role of ursolic acid in a murine model which entails the use of a commonly available, economical, and most mechanistically studied model, that is, gentamicin-induced nephrotoxicity in normal Wistar albino rats.

\section{Materials and Methods}

2.1. Animals. Wistar albino rats of either sex, weighing 150$200 \mathrm{~g}$, were used for the study. Animals were housed in standard environmental conditions $\left(22 \pm 3^{\circ} \mathrm{C}, 55 \pm 5 \%\right.$ humidity and a $12 \mathrm{~h}$ light/dark cycle) and fed with standard rodent diet and water ad libitum. The study was approved by the Institutional Animal Ethics Committee, Kasturba Medical College, Mangalore, Manipal University.

2.2. Drugs. Gentamicin sulfate (Piramel Health Care Ltd.) dissolved in normal saline was used to induce renal damage. The test drug, Ursolic acid (Sigma Aldrich Chemicals Pvt. Ltd., UK) was dissolved in 14\% DMSO, and administered orally in a dose of $2 \mathrm{mg} / \mathrm{kg}, 5 \mathrm{mg} / \mathrm{kg}$, and $10 \mathrm{mg} / \mathrm{kg}$.

2.3. Experiment Protocol. After acclimatization, the animals were divided randomly into five groups (6 rats/each group) and placed in metabolic cages separately for collecting 24hour urine samples. After collecting the first urine samples, the animals were grouped according to Table 1. The drugs were administered for a total duration of 8 days. The test drug ursolic acid was started 3 days prior to the commencement of the study.

2.4. Sample Collection and Biochemical Assays. Twenty-four hours after the last injection, urine samples were collected and the animals were euthanized under ether anesthesia. Blood samples were collected by cardiac puncture for measuring urea and creatinine as an indicator of kidney damage, using urease (a nickel metalloenzyme that catalyzes the degradation of urea to ammonia and carbon dioxide), and Jaffé (the combined use of creatinine, amidohydrolase, and alkaline sodium picrate) methods, respectively [19].

2.5. Histopathological Examination. Kidneys from all the four groups were weighed and processed for histopathological evaluation. The kidneys fixed in 10\% neutral buffered formalin were processed and embedded in paraffin wax and sections were taken using a microtome. Sections ( 5 microns) were then stained with haematoxylin and eosin and examined under light microscope. They were evaluated and assigned scores as follows:

Score $0=$ Normal,

Score 1 = Areas of focal granulovacuolar epithelial cell degeneration and granular debris in tubular lumens with or without evidence of tubular epithelial cell desquamation of small foci $(<1 \%$ of total tubule population),

Score 2 = Tubular epithelial necrosis and desquamation easily seen but involving less than half of cortical tubules,

Score 3 = More than half of proximal tubules showing desquamation of necrosis but involved tubules easily found, and

Score $4=$ Complete or almost complete tubular necrosis [11].

2.6. Statistical Analysis. Data were expressed as mean \pm standard error of mean (SEM). Statistical evaluation was done using SPSS version (Version 17.0). The differences among treated groups were analyzed by one-way ANOVA followed by Tukey's test. A value of $P<0.05$ was considered statistically significant.

\section{Results}

In the present study, gentamicin $(80 \mathrm{mg} / \mathrm{kg})$ when injected for 8 consecutive days caused marked neph-rotoxicity as is evident from Table 2, showing significant $(P<$ $0.001)$ increase in serum urea $(162.33 \pm 9.92 \mathrm{mg} / \mathrm{dL})$, serum uric acid $(3.13 \pm 0.123 \mathrm{mg} / \mathrm{dL})$, serum creatinine $(6.85 \pm 0.348 \mathrm{mg} / \mathrm{dL})$, and blood urea nitrogen $(75.86 \pm$ $4.636 \mathrm{mg} / \mathrm{dL}$ ) as compared to normal control animals.

The test drug, ursolic acid showed a significant nephroprotective effect as evidenced by a decrease in the renal parameters, that is, Serum urea, uric acid, creatinine, and blood urea nitrogen levels when compared to the gentamicin-treated group. Moreover, the results as depicted in Table 2 also suggest an interesting dose-dependent renoprotective effect with the highest dose (i.e., $10 \mathrm{mg} / \mathrm{kg}$ ) almost reducing the levels of serum urea, creatinine, and uric acid to normal control levels.

The histological changes in the kidney of all the groups were graded and the results are expressed in Table 3. It is further evident from the microscopical study of kidney sections that the kidneys from the saline treated appeared histologically normal (Score 0) (Figure 1) whereas the 
TABLE 1: Various study groups and the drug dosages.

\begin{tabular}{ll}
\hline Groups & Drug treatment \\
\hline Control & Normal saline $(1 \mathrm{~mL} / \mathrm{kg}$, intraperitoneal) \\
Disease control & Gentamicin (dissolved in isotonic saline) $80 \mathrm{mg} / \mathrm{kg} /$ day [11] intraperitoneal \\
\multirow{2}{*}{ Test drug } & Ursolic acid $2 \mathrm{mg} / \mathrm{kg} /$ day per oral (administered for 3 days prior to and during treatment with gentamicin \\
& $80 \mathrm{mg} / \mathrm{kg}$ intraperitoneal) \\
Test Drug & Ursolic acid $5 \mathrm{mg} / \mathrm{kg} /$ day per oral (administered for 3 days prior to and during treatment with gentamicin \\
& $80 \mathrm{mg} / \mathrm{kg}$ intraperitoneal) \\
Test Drug & Ursolic acid $10 \mathrm{mg} / \mathrm{kg} /$ day per oral (administered for 3 days prior to and during treatment with gentamicin \\
& $80 \mathrm{mg} / \mathrm{kg}$ intraperitoneal) \\
\hline
\end{tabular}

TABLE 2: Effect of gentamicin and ursolic acid on serum urea, uric acid, creatinine, and blood urea nitrogen levels.

\begin{tabular}{|c|c|c|c|c|c|}
\hline Parameters & $\begin{array}{l}\text { Control } \\
\text { group }\end{array}$ & $\begin{array}{l}\text { Gentamicin } \\
\text { group }\end{array}$ & $\begin{array}{l}\text { Ursolic acid } \\
2 \mathrm{mg} / \mathrm{kg}\end{array}$ & $\begin{array}{l}\text { Ursolic acid } \\
5 \mathrm{mg} / \mathrm{kg}\end{array}$ & $\begin{array}{l}\text { Ursolic acid } \\
10 \mathrm{mg} / \mathrm{kg}\end{array}$ \\
\hline $\begin{array}{l}\text { Serum urea } \\
(\mathrm{mg} / \mathrm{dL})\end{array}$ & $41.17 \pm 0.703$ & $162.33 \pm 9.922^{*}$ & $137.83 \pm 4.643^{* *}$ & $99 \pm 2.646^{* *}$ & $41.33 \pm 2.692^{* *}$ \\
\hline $\begin{array}{l}\text { Serum uric } \\
\text { acid }(\mathrm{mg} / \mathrm{dL})\end{array}$ & $1.62 \pm 0.305$ & $3.13 \pm 0.123^{*}$ & $2.42 \pm 0.108^{* *}$ & $1.57 \pm 0.128^{* *}$ & $1.32 \pm 0.14^{* *}$ \\
\hline $\begin{array}{l}\text { Serum } \\
\text { Creatinine } \\
(\mathrm{mg} / \mathrm{dL})\end{array}$ & $0.58 \pm 0.075$ & $6.85 \pm 0.348^{*}$ & $5.63 \pm 0.390^{* *}$ & $2.42 \pm 0.295^{* *}$ & $0.92 \pm 0.054^{* *}$ \\
\hline $\begin{array}{l}\text { Blood urea } \\
\text { nitrogen } \\
\text { levels } \\
(\mathrm{mg} / \mathrm{dL})\end{array}$ & $19.24 \pm 0.329$ & $75.86 \pm 4.636^{*}$ & $64.41 \pm 2.17^{* *}$ & $46.26 \pm 1.236^{* *}$ & $19.31 \pm 1.258^{* *}$ \\
\hline
\end{tabular}

gentamicin-treated group showed tubular epithelial loss with intense granular degeneration involving $>50 \%$ renal cortex as depicted in Figure 2. In addition to the tubular epithelial loss, some of the tubular epithelium contains tubular casts (Score 4). The histomorphology of rats treated with ursolic acid showed moderate tubular epithelial degeneration with desquamation in patchy areas of the renal cortex (Score 2). Treatment with the two lower doses of ursolic acid appeared to mitigate the severity of the gentamicin treatment-induced renal necrosis (Score of 2-3, resp.); whereas the high dose treatment almost completely protected the histological features of kidney from gentamicin-induced alterations as depicted in Figures 3, 4 and 5.

\section{Discussion}

In the present study, we investigated the effect of ursolic acid on gentamicin-induced acute renal failure in a murine model. Results of this study confirmed that gentamicin at a dose of $80 \mathrm{mg} / \mathrm{kg}$ produces significant nephrotoxicity as evidenced by increase in blood urea nitrogen, serum creatinine, urea and uric acid, and renal tubular necrosis which corroborated with previous reports $[8,11-14,17]$. Pretreatment with ursolic acid provided marked functional and histological protection against acute renal damage in rats treated with gentamicin. Increase in blood urea nitrogen and serum urea, uric acid, and creatinine, induced by gentamicin was prevented by ursolic acid. This study revealed that orally-administered ursolic acid has a significant and dosedependent protective effect in gentamicin-induced nephrotoxicity in rats. The significance of ursolic acid in the treatment of nephrotoxicity is further increased because of its diuretic potential as well as its lower toxicity [20].

A relationship between oxidative stress and nephrotoxicity has been well-demonstrated in many experimental animal models [21]. In gentamicin-treated rats, a significant increase in lipid peroxidation products malondialdehyde (MDA) suggesting that the involvement of oxidative stress has been reported. A role of lipid peroxidation in gentamicin-induced acute renal failure has also been described in previous studies. Moreover, pretreatment of rats with hydroxyl radical scavengers has been shown to protect against gentamicininduced acute renal failure [11].

Paracetamol-induced nephrotoxicity is proposed to be due to the overproduction of nitric oxide (NO) and a marked reduction of hepatic and renal intracellular glutathione (GSH) levels [22]. The cytoprotection imparted by oleanolic acid, a triterpenoid closely related to ursolic acid in paracetamol-induced nephrotoxicity in rats was proposed to inhibit the overproduction of $\mathrm{NO}$ and to maintain the level of intracellular GSH through its potent antioxidant activities [22]. Gentamicin is known to decrease the activities of catalase, glutathione peroxidase, and the level of reduced glutathione [23]. Ursolic acid which is an important 
TABLE 3: Histopathological features of kidneys of rats of different treatment groups.

\begin{tabular}{lccccc}
\hline Histopathological feature & Control group & Gentamicin group & $\begin{array}{c}\text { Ursolic acid } \\
2 \mathrm{mg} / \mathrm{kg}\end{array}$ & $\begin{array}{c}\text { Ursolic acid } \\
5 \mathrm{mg} / \mathrm{kg}\end{array}$ & $\begin{array}{c}\text { Ursolic acid } \\
10 \mathrm{mg} / \mathrm{kg}\end{array}$ \\
\hline Glomerular congestion & - & 4 & 2 & 1 & 1 \\
Blood vessel congestion & - & 3 & 2 & 1 & 1 \\
Interstitial edema & - & 3 & 1 & 2 & 0 \\
Inflammatory cells & - & 2 & 2 & 1 & 0 \\
Necrosis and tubular casts & - & 4 & 1.6 & 1.2 & 0.4 \\
Average score & 0 & 3.2 & & 1 & 1 \\
\hline
\end{tabular}

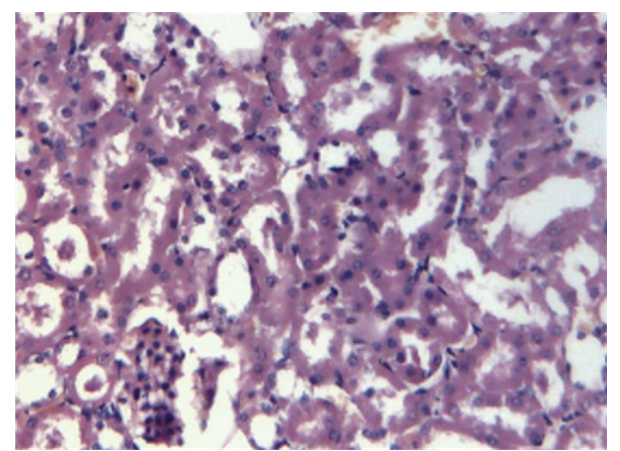

FIgure 1: Photomicrograph of kidney sections showing normal kidney (40X, H \& E).

component of Ocimum sanctum has been shown to inhibit lipid peroxidation and protect against free-radical-induced adriamycin toxicity [24]. Treatment of mice with ursolic acid inhibits mitochondrial lipid peroxidation in tumorbearing rats and returns the increased superoxide dismutase to normal levels [25]. Also, its antioxidant activity has been partially held responsible for its preventive and therapeutic effects on acute hepatic injury in rats [26]. Therefore, it is not unreasonable to assume that the nephroprotection shown by ursolic acid in gentamicin-induced nephrotoxicity is mediated through its potent antioxidant effects that help to preserve intracellular GSH levels. The antioxidant activity of ursolic acid might have contributed to its nephroprotective effect by inhibiting gentamicin-induced lipid peroxidation.

However, other mechanisms of protection [27] like inactivation of the aminoglycoside by electrostatic complex formation or preventing its binding to the brush border membrane or by forming complexes at acidic $\mathrm{pH}$ and preventing phospholipid overloading in lysosomes cannot be negated also. Additional studies are warranted in order to test these assumptions, such as the measurement of gentamicin urinary excretion, the examination of gentamicin, and ursolic acid interactions with brush border membranes, and the effect of treatment on intracellular $\mathrm{Ca}^{2+}$. Further studies exploring and linking the antioxidant activities to the nephroprotective effect and evaluation of glomerular filteration rate in ursolic-acid-treated rats might shed more light on the mechanism of renoprotective action of ursolic acid. Hence such investigations should be conducted in order

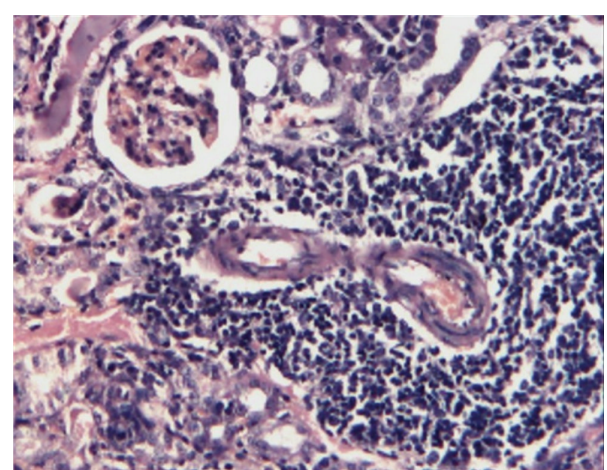

FIGURE 2: Photomicrograph of kidney sections of only gentamicintreated group: showing kidney tissue with glomerular congestion, inflammatory cell infiltration, necrosis—score 3.2 (40X, H \& E).

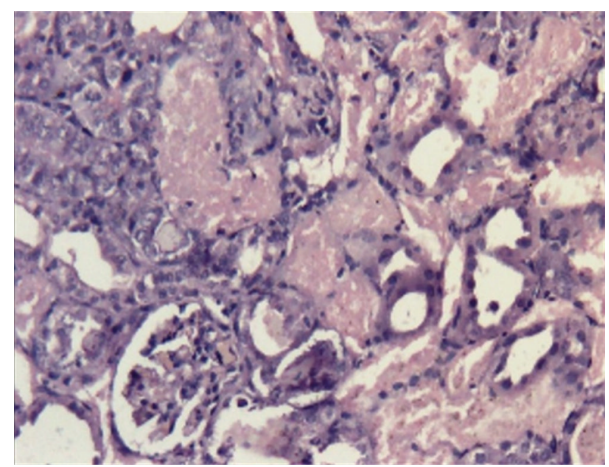

FIgure 3: Photomicrograph of kidney sections ursolic acid $(2 \mathrm{mg} / \mathrm{kg})$ treated group: showing near total necrosis-score 1.6 (40X, H \& E).

to better characterize the attenuation of gentamicin-induced nephrotoxicity by ursolic acid.

\section{Conclusion}

To conclude, this study provides scientific evidence of the nephroprotective effects of orally administered ursolic acid in a murine model employing gentamicin as a toxicant that directly induces renal damage. It further proposes that observed protective effects of ursolic acid in gentamicin nephrotoxicity could be attributed to its well-known antioxidant potential. 


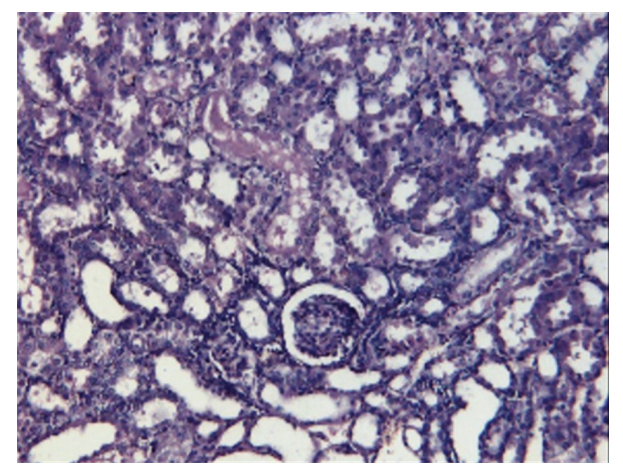

Figure 4: Photomicrograph of kidney sections ursolic acid $(5 \mathrm{mg} / \mathrm{kg})$ treated group: showing necrosis but involved tubule easily found-score $1.2(10 \mathrm{X}, \mathrm{H} \& \mathrm{E})$.

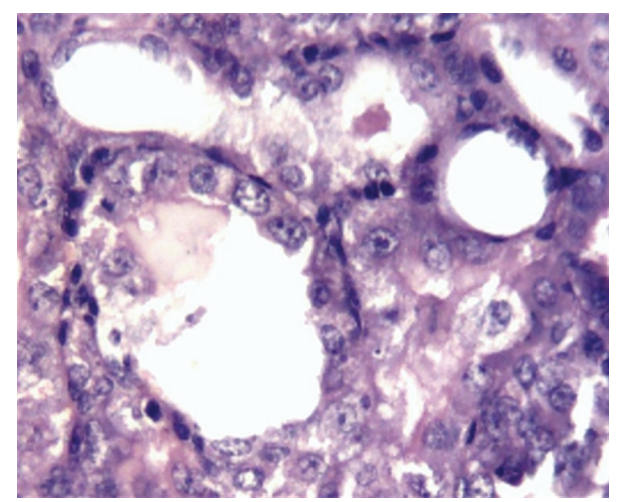

FIGURE 5: Photomicrograph of kidney sections ursolic acid $(10 \mathrm{mg} / \mathrm{kg})$ treated group: showing dilated PCT where necrotic cells have been shed—score 0.4 (40X, H \& E).

\section{Acknowledgment}

The authors acknowledge with gratitude the financial aid received from Indian Council of Medical Research-Short Term Student Research grant.

\section{References}

[1] R. A. Swain and B. Kaplan-Machlis, "Therapeutic uses of vitamin E in prevention of atherosclerosis," Alternative Medicine Review, vol. 4, no. 6, pp. 414-423, 1999.

[2] M. P. Mingeot-Leclercq and P. M. Tulkens, "Aminoglycoside neprotoxicity," Antimicrobial Agents and Chemotherapy, vol. 43, no. 5, pp. 1003-1012, 1999.

[3] E. J. Begg and M. L. Barclay, "Aminoglycosides-50 years on," British Journal of Clinical Pharmacology, vol. 39, no. 6, pp. 597603, 1995.

[4] R. S. Edson and C. L. Terrell, "The aminoglycosides," Mayo Clinic Proceedings, vol. 74, no. 5, pp. 519-528, 1999.

[5] B. J. Khoory, V. Fanos, A. Dall'Agnola, and L. Cataldi, "Aminoglycosides, risk factors and neonatal kidney," Pediatria Medica e Chirurgica, vol. 18, no. 5, pp. 495-499, 1996.

[6] F. Rougier, D. Claude, M. Maurin, and P. Maire, "Aminoglycoside nephrotoxicity," Current Drug Targets, vol. 4, no. 2, pp. 153-162, 2004.
[7] S. Cuzzocrea, E. Mazzon, L. Dugo et al., "A role for superoxide in gentamicin-mediated nephropathy in rats," European Journal of Pharmacology, vol. 450, no. 1, pp. 67-76, 2002.

[8] A. A. Al-Majed, A. M. Mostafa, A. C. Al-Rikabi, and O. A. AlShabanah, "Protective effects of oral arabic gum administration on gentamicin-induced nephrotoxicity in rats," Pharmacological Research, vol. 46, no. 5, pp. 445-451, 2002.

[9] R. J. Reiter, D. X. Tan, R. M. Sainz, J. C. Mayo, and S. LopezBurillo, "Melatonin: reducing the toxicity and increasing the efficacy of drugs," Journal of Pharmacy and Pharmacology, vol. 54, no. 10, pp. 1299-1321, 2002.

[10] B. Halliwell and J. M. C. Gutteridge, Free Radicals in Biology and Medicine, Clarendon Press, Oxford, UK, 1999.

[11] K. V. Kumar, M. U. R. Naidu, A. A. Shifow, and K. S. Ratnakar, "Probucol protects against gentamicin-induced nephrotoxicity in rats," Indian Journal of Pharmacology, vol. 32, no. 2, pp. 108-113, 2000.

[12] I. T. Abdel-Raheem, A. A. Abdel-Ghany, and G. A. Mohamed, "Protective effect of quercetin against gentamicin-induced nephrotoxicity in rats," Biological and Pharmaceutical Bulletin, vol. 32, no. 1, pp. 61-67, 2009.

[13] I. Yaman and E. Balikci, "Protective effects of Nigella sativa against gentamicin-induced nephrotoxicity in rats," Experimental and Toxicologic Pathology, vol. 62, no. 2, pp. 183-190, 2010.

[14] G. V. Harlalka, C. R. Patil, and M. R. Patil, "Protective effect of Kalanchoe pinnata pers. (Crassulaceae) on gentamicininduced nephrotoxicity in rats," Indian Journal of Pharmacology, vol. 39, no. 4, pp. 201-205, 2007.

[15] S. B. Mahato, S. K. Sarkar, and G. Poddar, "Triterpenoid saponins," Phytochemistry, vol. 27, no. 10, pp. 3037-3067, 1988.

[16] J. Liu, "Pharmacology of oleanolic acid and ursolic acid," Journal of Ethnopharmacology, vol. 49, no. 2, pp. 57-68, 1995.

[17] A. Jain and A. K. Singhai, "Effect of Momordica dioica Roxb on gentamicin model of acute renal failure," Natural Product Research, vol. 24, no. 15, pp. 1379-1389, 2010.

[18] R. P. Chandragouda, R. B. Jadhav, P. K. Singh, S. Mundada, and P. R. Patil, "Protective effect of oleanolic acid on gentamicin induced nephrotoxicity in rats," Phytotherapy Research, vol. 24, no. 1, pp. 33-37, 2010.

[19] T. B. Mohammed and H. R. Sadeghnia, "Protective effect of safranal against gentamicin-induced nephrotoxicity in rat," Iranian Journal of Medical Sciences, vol. 34, no. 4, pp. 285-288, 2009.

[20] L. O. Somova, A. Nadar, P. Rammanan, and F. O. Shode, "Cardiovascular, antihyperlipidemic and antioxidant effects of oleanolic and ursolic acids in experimental hypertension," Phytomedicine, vol. 10, no. 2-3, pp. 115-121, 2003.

[21] A. A. Shifow, K. V. Kumar, M. U. R. Naidu, and K. S. Ratnakar, "Melatonin, a pineal hormone with antioxidant property, protects against gentamicin-induced nephrotoxicity in rats," Nephron, vol. 85, no. 2, pp. 167-174, 2000.

[22] A. O. Abdel-Zaher, M. M. Abdel-Rahman, M. M. Hafez, and F. M. Omran, "Role of nitric oxide and reduced glutathione in the protective effects of aminoguanidine, gadolinium chloride and oleanolic acid against acetaminophen-induced hepatic and renal damage," Toxicology, vol. 234, no. 1-2, pp. 124-134, 2007.

[23] E. O. Farombi and M. Ekor, "Curcumin attenuates gentamicin-induced renal oxidative damage in rats," Food and Chemical Toxicology, vol. 44, no. 9, pp. 1443-1448, 2006. 
[24] S. Balanehru and B. Nagarajan, "Protective effect of oleanolic acid and ursolic acid against lipid peroxidation," Biochemistry International, vol. 24, no. 5, pp. 981-990, 1991.

[25] Y. A. Dominic and M. Subbaiyan, "Studies on mitochondrial lipid peroxidation in tumour-bearing rats treated with ursolic acid and ursolic acetate," Medical Science Research, vol. 21, no. 5, pp. 213-215, 1993.

[26] X. H. Ma, Y. C. Zhao, L. Yin, R. L. Xu, D. W. Han, and M. S. Wang, "Studies on the preventive and therapeutic effects of ursolic acid (UA) on acute hepatic injury in rats," Acta Pharmaceutica Sinica, vol. 21, no. 5, pp. 332-335, 1986.

[27] D. Beauchamp, G. Laurent, L. Grenier et al., "Attenuation of gentamicin-induced nephrotoxicity in rats by fleroxacin," Antimicrobial Agents and Chemotherapy, vol. 41, no. 6, pp. 1237-1245, 1997. 

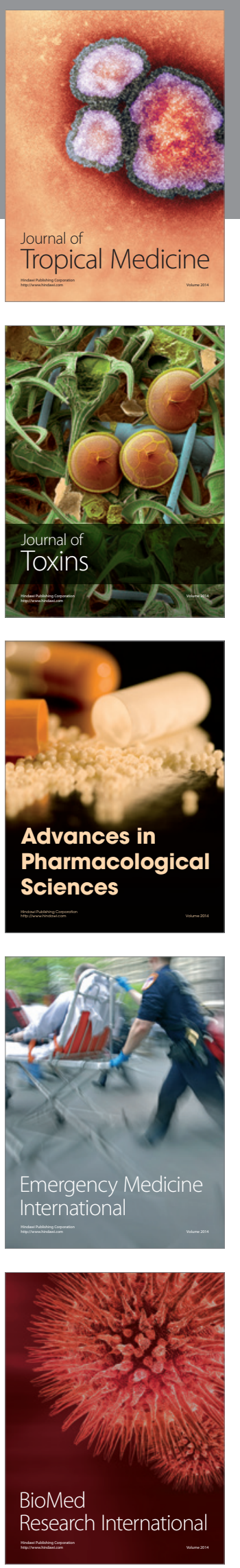
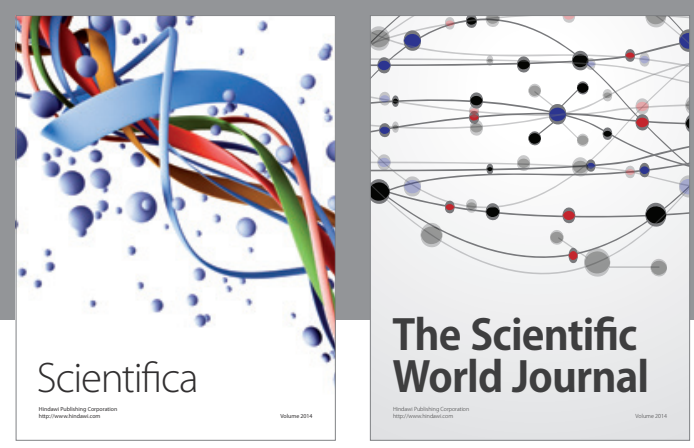

The Scientific World Journal
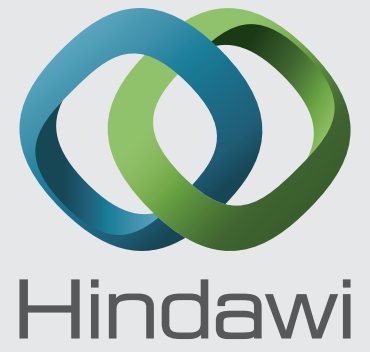

Submit your manuscripts at

http://www.hindawi.com
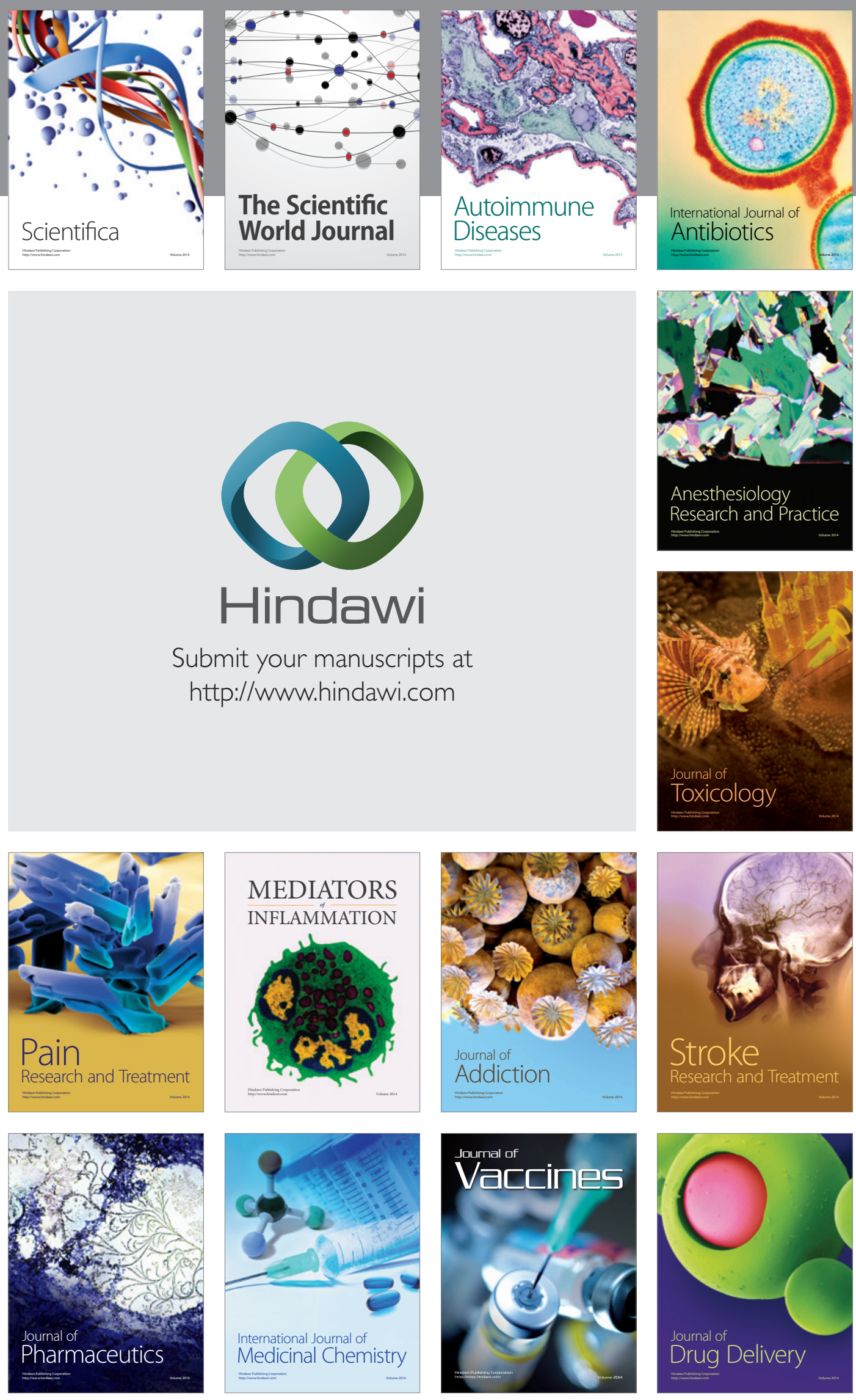